\title{
MARÍA JIMENA SCHERE. El par cómico: un estudio sobre la persuasión cómica en las comedias tempranas de Aristófanes, Santiago Arcos Editor y Editorial de la Facultad de Filosofía y Letras, Ciudad Autónoma de Buenos Aires, 2018, 334 pp.
}

\author{
Susana Aguirre \\ Universidad Nacional de Cuyo, Argentina
}

La publicación de esta obra condensa y da forma a años de investigación y reflexión acerca del corpus aristofánico. Antes y después de la defensa de su tesis doctoral, en 2012, Jimena Schere ha trabajado sobre la dimensión polémica de la comedia griega. En este volumen demuestra cómo esa dimensión polémica se sirve, sobre todo en las cuatro comedias más tempranas que tenemos de Aristófanes, de un recurso muy identificable: el par cómico. La autora entiende por par cómico a la dupla formada por un polo positivo y un polo negativo, protagonista burlador y antagonista burlado, respectivamente. Se limita principalmente al análisis de estas cuatro primeras obras, ya que es en las que considera que este recurso aparece de manera más manifiesta.

En el Capítulo I, “Discurso cómico y argumentación. Perspectivas teóricas” (p. 13), Schere repasa, de manera clara y prolija, las principales corrientes teóricas sobre la naturaleza misma del humor, partiendo del problema de lo cómico en Platón y Aristóteles para llegar a la reflexión filosófica y literaria desde el siglo dieciocho hasta nuestros días. En el apartado 3 de este capítulo ("Humor literario y argumentación"), detalla cuidadosamente las posibilidades del uso polémico de la sátira y la parodia, así como las nuevas perspectivas de análisis de la relación entre argumentación y literatura. El cuarto apartado, "Los recursos de la persuasión cómica en la ficción literaria”, distingue los rasgos que hacen que el humor sea más o menos corrosivo y los sintetiza en un cuadro, al que se hará alusión repetidas veces cuando se llegue al análisis concreto de las comedias. Finalmente, se justifica en qué medida el uso de tópicos cómicos puede ser un recurso argumentativo. De este modo completa el marco teórico general literario, retórico y lingüístico que fundamenta esta lectura de las obras.

El Capítulo II, "Discurso cómico y argumentación en la comedia de Aristófanes. Aproximaciones críticas" (p. 53) fija la posición de la autora a favor de la posibilidad de un contenido político deliberado en las obras tempranas del comediógrafo, después de repasar las posiciones y fundamentos de esta controversia. Precisa también el uso de determinados recursos, el humor satírico y el humor paródico, ya analizados en general, esta vez en los textos que se trabajarán. Finalmente introduce el eje de esta obra: la presencia del par cómico. En esta primera manifestación, aclara que se basa en la noción de Beltrametti (2000), desarrollada de manera personal.

"El par cómico en la tradición literaria griega" (p. 75) es el título del Capítulo III, donde se aprecian los antecedentes de este esquema: el protagonista burlador y el antagonista burlado. Aquí se detallan y analizan sus apariciones en la poesía homérica: los episodios de Odiseo y el Cíclope, Odiseo e Iro, Odiseo y Tersites. Luego se estudia su presencia en la fábula y en la poesía yámbica (p. 86 y p. 92, respectivamente). Se concluye con una interesante sistematización de las relaciones de poder en los pares cómicos tradicionales (p. 97) y sus características comunes (p. 99). 
Ya entre los capítulos IV y VII se trata el funcionamiento del par cómico específicamente en cada pieza aristofánica y se puede así apreciar cómo este autor retoma un recurso tradicional sobre el cual realiza aportes definitivos, como es el cambio de valor del personaje poderoso. El Capítulo IV (p. 103) trata el caso de Acarnienses, mediante el análisis de cómo, sobre todo en las llamadas escenas agonales, se van conformando tanto el polo positivo del par cómico (Diceópolis) como el polo negativo (Lámaco). El detalle y la valoración de las distintas variables del humor que recaen sobre cada uno de estos personajes permiten apreciar el cómo y el para qué de esta conformación y su mensaje político.

Caballeros es la obra analizada en el Capítulo V (p. 153), el capítulo más extenso. Aquí se valora en qué medida el aporte de Schere complementa los estudios sobre el héroe cómico, ya que justamente el protagonista, el Morcillero, es un personaje enigmático, cuya coherencia llega a ser difícil de entender si uno se limita a analizarlo en su rol de héroe. Sin embargo, su posición de polo positivo en el par cómico, que se va desarrollando a lo largo de las distintas escenas agonales, sí tiene una consistencia más fácil de percibir. Se complementa el capítulo con un estudio sobre el aprovechamiento de los tópicos cómicos en la obra.

El Capítulo VI (p. 229), centrado en Avispas, resulta particularmente interesante. En este caso la percepción del funcionamiento del par cómico ayuda a dilucidar una cuestión aún controversial en esta comedia: nada menos que la identidad del héroe. El análisis de la autora, no solo del agón sino de toda la obra, le permite señalar sin dudas a Bdelicleón como el polo positivo del par cómico, y por lo tanto el protagonista, y a Filocleón como el polo negativo, blanco principal de la comedia. Con esto, Schere se separa de la crítica actual mayoritaria, que tiende a adjudicarle el rol de héroe cómico a Filocleón. Las pocas erratas significativas del volumen, unas confusiones en nombres de personajes, se dan en este capítulo (p. 247 y p. 251, Bdelicleón por Filocleón).

Finalmente, en el Capítulo VII, llamado "El par cómico en Paz y sus proyecciones en Lisistrata" (p. 267) podemos apreciar cómo este recurso intensifica la oposición entre Trigeo y Pólemos. Si bien el humor está utilizado de una manera menos corrosiva, esto es coherente con su función de refuerzo y celebración de la propuesta de paz (la cual estaba en tratativas), antes que con una función de propaganda pacifista. Es notable cómo este esquema vuelve a ser utilizado en Lisistrata, esta vez con la protagonista femenina como polo positivo y el Consejero como polo negativo. La similitud temática podría explicar la vuelta a un recurso que aparentemente ya estaba más en desuso.

El Capítulo VIII, “Conclusiones” (p. 297) resume y esquematiza lo analizado y permite reconocer la gran coherencia de los planteos de la autora. La bibliografía (p. 305) es extensa, completa y variada.

Resulta muy valioso el aporte de este estudio sistemático, de largo alcance, sobre comedia antigua. Las afirmaciones se ven sólidas, enmarcadas en la lectura crítica de la ingente bibliografía ya que, aunque se tiene en cuenta el estado de la cuestión, no se siguen pasivamente las posiciones predominantes. Sobre todo se percibe la solidez que da el anclaje en el conocimiento del texto (aparentemente todas las traducciones son propias). El esquema que se propone se descubre en las obras, no se fuerza. En resumen, esperamos que este libro tenga la difusión que merece por mostrar lo que debe ser un texto de crítica literaria: una propuesta de lectura profunda y responsable, que ayuda a la comprensión y, por qué no, al disfrute de este humor tan lejano y tan actual. 